\title{
Exploring teachers' needs and the existing barriers to the adoption of Learning Design methods and tools: a literature survey
}

\section{Authors}

Francesca Maria Dagnino, Yannis Dimitriadis, Francesca Pozzi, Juan Asensio-Pérez, Bartolomé Rubia-Avi

Francesca M. Dagnino is a research fellow at the Istituto per le Tecnologie Didattiche of the Consiglio Nazionale delle Ricerche (CNR). Her main research interests are game based learning, learning design (LD), and ICT-based solutions for cultural heritage education.

Yannis A. Dimitriadis is currently a full professor of telematics engineering at the University of Valladolid. His research interests include technological support to the orchestration of ComputerSupported Collaborative Learning (CSCL) processes, LD, and learning analytics.

Francesca Pozzi is a researcher at the Istituto per le Tecnologie Didattiche of the Consiglio Nazionale delle Ricerche, Italy. Her primary research interests include CSCL, LD and ICT-based solutions for cultural heritage education, evaluation and learning analytics, MOOCs.

Juan I. Asensio-Pérez is currently associate professor of telematics engineering at the University of Valladolid. His research interests within the field of Technology-Enhanced Learning include: LD, CSCL orchestration, and the application of Augmented Reality technologies for the support of CSCL situations across multiple virtual and physical spaces.

Bartolomé Rubia-Avi, is currently Associate Professor at the University of Valladolid (Spain), and Director of Centre for Transdisciplinary Research in Education (CETIE-UVa). His research interest is in the educational implications of CSCL scenarios, with special attention to new ways of evaluating these particular settings.

\section{Abstract}

Learning Design (LD) is oriented to support teachers in designing their teaching with the aim to provide a sound pedagogical background and to make effective use of resources and technologies. In spite of the significant number of LD approaches and tools proposed so far, their adoption is still very limited and this represents an unsolved challenge in the field of LD. This paper presents a systematic review of the literature about learning design tools, tackling the issue of adoption from two points of view: teachers' needs in relation to LD tools and methods and possible barriers to their adoption. The review includes only research papers where teachers' behaviours and opinions are directly explored and not purely theoretical papers. The search included five main academic databases in Technology Enhanced Learning (TEL) plus a search on Google about project reports; the resulting corpus included 423 papers: 26 of these, plus 3 reports were included in the final list for the analysis. The review provides a systematic overview of the knowledge developed in the LD field, focusing on a set of research gaps that need further exploration in the future.

Keywords: Learning Technology, Learning Design, Authoring software

\section{Introduction}

In the last 15 years research in Learning Design (LD) has gathered momentum in the TEL field, because of the growing need to support teachers in conceiving technology-enhanced educational 
interventions, built on a sound pedagogical background (Mor \& Craft, 2012). Indeed, the community has recognized that in the knowledge society, education has been undergoing important changes in terms of rising learning needs, environments and technological opportunities (Kalantzis \& Cope, 2010). In the current panorama, a shared vision is that teachers ought to devote more time to designing their teaching interventions so as to inform them with thorough pedagogical decisions and to make the most of the growing use of technologies (Goodyear, 2015; Laurillard, 2012).

Following these considerations, part of the research effort in LD has been devoted to developing different methods and tools; some of these are linked to a specific pedagogical approach or theory, while others were theory-independent, tailored or not to specific learning contexts, adopting formal (like IMS-LD specifications) or intuitive visual and/or textual representations and operating at different level of design (micro or macro) (Conole, 2013). This number of different options reflects the richness of the research in the field and its level of maturity but at the same time it opens several challenges (Mor, Craft, \& Maina, 2015). Certainly, as Conole (2015) highlights, a crucial point is finding what mediating artifacts (tools and symbolic artifacts, proposed from the point of view of Vygotsky's theoretical framework, 1962 and 1978) are used already by practitioners and what new artifacts can be created to support and guide the design process. In fact, despite considerable research and development effort, the adoption of LD methods and tools still remains limited (Asensio-Pérez, Dimitriadis, Prieto, Hernández-Leo, \& Mor, 2014, Hernández-Leo, et al., 2018). This issue has been explored by several researchers, frequently in relation to specific cases (e.g. the specifications of IMS-LD, Neumann et al., 2010).

According to Asensio-Pérez and colleagues (2017), aspects that seem to affect adoption pertain to three areas: [1] characteristics of LD tools: e.g. flexibility, support to all the phases of the design process and for teachers as members of designer communities (Bennett, Agostinho, \& Lockyer, 2015; Hernández-Leo, Chacón, Prieto, Asensio-Pérez, \& Derntl, 2013; Voogt et al., 2011); [2] teachers' mindset (Dimitriadis \& Goodyear, 2013); [3] adequate training (Bennett, Agostinho \& Lockyer, 2017).

To the best of our knowledge, despite the attention devoted to the issue, a complete state of the art of the research on factors affecting adoption of LD methods and tools has not yet been performed. Just one systematic literature review has been recently conducted with the aim of sketching teachers' actual perception of computer systems supporting LD and teachers' needs (Celik \& Magoulas, 2016). Teachers' turned out to be very positive towards LD tools but, unfortunately, existing barriers to adoption do not emerge from the review. The present contribution aims to go further and broaden the focus with respect to the above cited review, collecting evidence from the literature regarding teachers' needs but also existing barriers to adoption, seeking to provide a double perspective on the phenomenon and to identify possible research gaps. The research questions driving this literature review are the following: (1) "What are (school and university) teachers' needs for LD tools?"; (2) "What are the main barriers to the adoption of LD tools and the proposed design practices?".

Our systematic literature review has covered the five leading academic databases in blended learning; additionally, project reports have been searched on Google. Out of the initial collection of 423 papers 26 were included in the in-depth analysis, as well as three projects reports.

The following section presents the methodology adopted in the systematic review. Afterwards, results are reported organized in two areas: teachers' needs and barriers to adoption. In the last section the main conclusions are drawn from the analysis, and some recommendations are given for future research in the field. 


\section{Methodology}

To carry out this literature review the guidelines proposed by Kitchenham and Charters (2007) were followed. These are conceived for the software engineering research area but are based on existing guidelines in other disciplines, including social sciences, and therefore they can also be considered applicable to other research domains, such as TEL (see for example Rodriguez-Triana et al., 2017).

To conduct the review, five main electronic database were selected: ACM digital library, IEEE Xplore, Scopus, SpringerLink, Web of Science. In addition, Google was consulted in order to find project reports in the field of LD. The time period (2010-2017) was set in order to narrow the query.

The search string used includes the macro research area (learning design or design for learning) and two other groups of terms adopted to narrow the search to papers about LD artifacts and that consider users (teachers or designers or practitioners). The final search string resulted as follows: ("learning design" OR "design for learning") AND (tool OR "computer system" OR software) AND (teacher* OR designer* OR practitioner*). The search string (or a corresponding version, according to the format required by the different databases) was used in relation to title, abstract and keywords (except in SpringerLink, where the search was run, necessarily, on the full texts). The search was conducted on April 20th 2017. A total of 2408 records were retrieved, including journal and conference papers and book chapters.

Records retrieved through the search step passed through two stages of analysis. Beforehand, due to the high number of records retrieved from Springer, a preliminary selection was carried out on the corpus to reduce it; a manual search of the string was conducted on titles, abstracts and keywords. Duplicates were, then, removed, resulting in a total of 423 papers. As a first step in selection, the title and abstract were read to find papers dealing with barriers to LD tool adoption and teachers' needs. Selection was carried out in relation to the relevance of the contribution to the topics explored and, if it was possible to infer them, to the inclusion/exclusion criteria:

Inclusion criteria:

- Primary study conducting quantitative and/or qualitative research on the topics

- Language: English

Exclusion criteria:

- Primary study without research data.

Twenty-six papers out of 423 passed the first stage and were selected. This list was augmented with one paper cited by Celik and Magoulas (2016) that did not result from the search but is clearly of interest and three project reports, related to the METIS project ${ }^{1}$.

The selected works were read and 20 papers and 2 reports $^{2}$ proved to meet the inclusion criteria, providing data about the two research questions (Figure 1).

The methodology adopted for the analysis was both inductive and deductive; starting from a theoretical background gained from the literature, the conceptual structure was enriched and refined by new elements derived from the analysis of the documents. Papers were read and tagged. Some

\footnotetext{
${ }^{1} \mathrm{http}: / /$ websites.cardet.org/metis/index.php/

2 The first METIS report "Report on first formative evaluation round. METIS Deliverable D5.2" was excluded since the results of the second evaluation round were available.
} 
key themes were already widely acknowledged and thoroughly discussed in the literature (e.g. flexibility in response to needs) and were used as pre-existing categories to tag the documents, others (e.g. teachers' motivation) emerged from the analysis and were added to the list of themes.

The adoption of a tool for LD can, in some way, be compared with technology adoption in general, so after having listed the themes that emerged, these were analysed in light of Ertmers' conceptualization of first and second order barriers. The identified barriers will therefore be presented in these two categories. The results are presented in the following section.

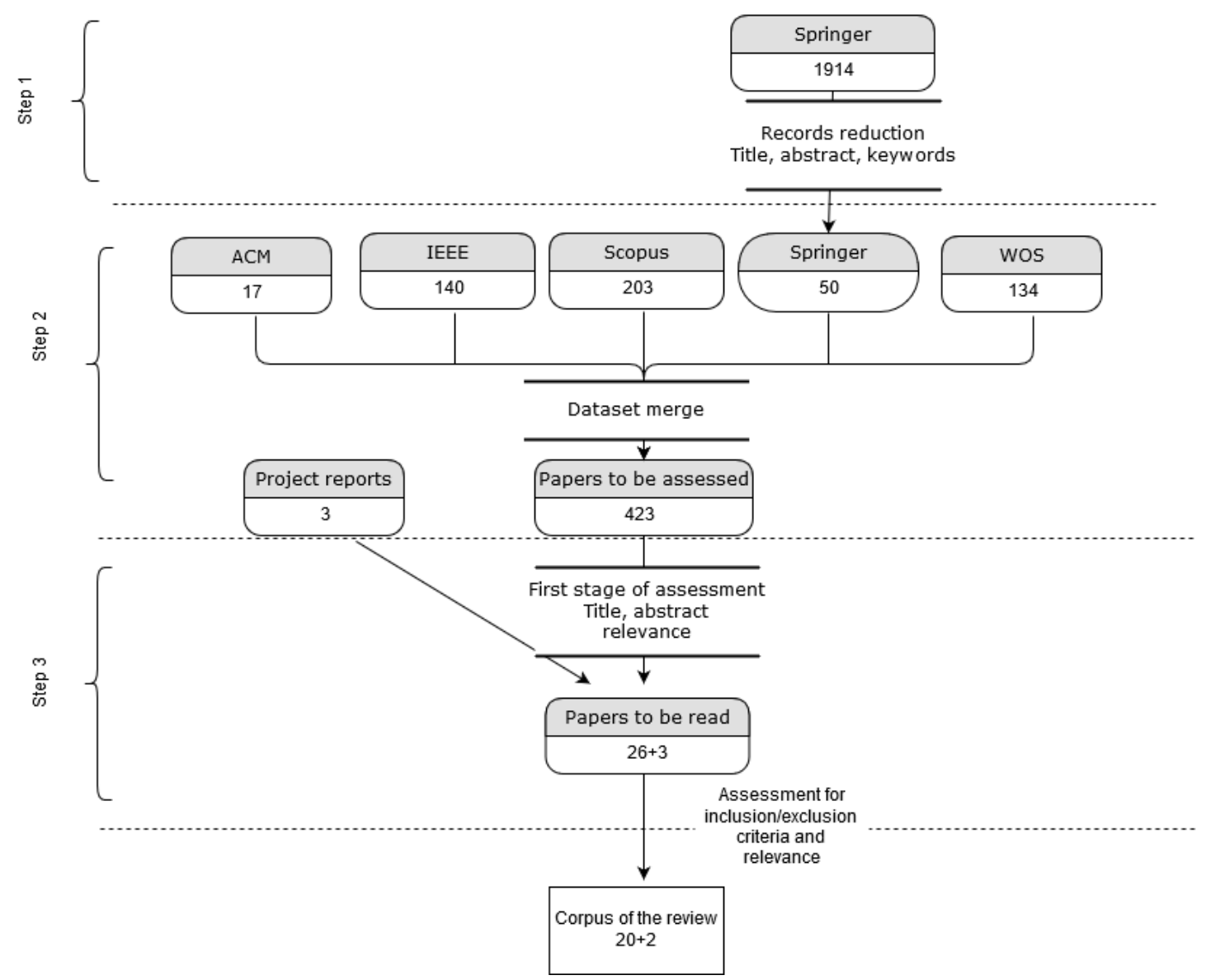

Figure 1 - Steps in the selection of papers

\section{Results}

Analysis of the 20 papers and 2 projects reports (listed in the Annex) leads us to sketch a panorama about teachers' needs in terms of LD tools features and reported barriers to adoption, grounded on teachers/practitioners' experiences and feedback on the LD tools already available and on the study of teachers' design practices.

The aims of the considered studies can be roughly divided in three categories:

a. Studies on tool perception/evaluation: 13 out of the 20 papers, and both reports, are devoted to evaluation of a specific tool, mainly in terms of perceived usefulness and/or ease of use. Studies were conducted during the period of training or immediately afterwards. Among the papers read, only Masterman and Manton (2011) attempted to draw more general considerations about the factors affecting adoption. Just one study compares teachers' perception of several tools and seeks 
to explore the obstacles in tool adoption (Prieto, Tchounikine, Asensio-Pérez, Sobreira, \& Dimitriadis, 2014).

b. Studies on users' needs: This category includes studies that collect users' needs as a main or secondary outcome (5 out of 20 ).

c. Analysis of design practices: In 3 out of the 20 papers, current Higher Education (HE) teachers' design practices are explored to identify the desirable characteristics for an LD tool.

The studies were mainly carried out in HE contexts (with teachers and/or students) or in groups including teachers/practitioners from different contexts (e.g. HE and Vocational Training), and therefore there is no basis for drafting specific needs for specific teacher categories.

\section{$R Q 1$. What are (school and university) teachers' needs for LD tools?}

In the papers analysed, teachers' needs are explored or inferred by the authors, even though the main focus of the research lays elsewhere. For example, in some papers needs were derived from analysis of the teachers' teaching practices (e.g. Bennett et al., 2015), while in others they were directly expressed as needs or in the form of requirements by the teachers themselves (e.g. Arpetti, Baranauskas, \& Leo, 2014a). Finally, in other papers needs were derived from the evaluation of tools (e.g. Conole, 2014, Pozzi et al., 2015b). In this section, we attempt to categorize these findings, to express them in a clear and organized way:

Flexibility: Flexibility is recognized as a key factor for adapting designs to different educational contexts and it is frequently cited in the literature as a desirable feature in an LD tool. In the analysed corpus of papers, it was cited by teachers as a positive aspect in the evaluation of an LD tool (Conole, 2014) and is considered a core quality not just at tool level but also at methodology level (Arpetti, Baranauskas, \& Leo, 2013). It is worth noting that this term assumed different meanings that will be explored in the following. In some cases, teachers call for tools that are theory and context independent. For example, in the process of collecting teachers' requirements for an ideal LD tool, Arpetti and colleagues (2014a) consider flexibility as central for allowing the reuse of designs and their revision and adaptation to educational needs.

In other cases, flexibility is contrasted with the structuring level of the tool and with the provided guidance; namely, the more structured a tool is (and the greater the guidance provided), the more constraints are embedded in the design process. Prieto and colleagues (2014) compared teachers' perceptions of two different LD tools (WebCollage and EDIT2) with two different levels of guidance; this comparison did not yield a conclusive position from teachers about this juxtaposition. Performing a set of interviews with University teachers about their design practices, Bennett and colleagues (2015) highlight that a tool should enable flexibility in the design process but, at the same time, provide guidance. Similarly, Laurillard and colleagues (2013) and Masterman \& Manton (2011) highlight that both flexibility and structuring could enhance the value of design support tools. Along the same line Levy (2015) concludes that there is value in developing design tools that have a high level of flexibility in relation to pedagogical choices.

Lastly, the need of flexibility was also expressed in terms of making the process of changing the designs once they were delivered smoother. This aspect refers to the situations in which the LD tool is integrated with a runtime environment or enables the delivery of the design in a certain learning environment. In such case, flexibility refers to the ability to come back to the original design and change it in the light of issues raised during the deliver. In particular, Prieto and colleagues (2013) report that teachers asked for more flexibility in terms of runtime changes; similarly, Hermans, 
Janssen, \& Koper (2016) identify the opportunity to easily switch between the design and runtime environments as highly desirable.

Support for reuse and adaptation of designs: The need for a tool supporting reuse and adaptation of designs is mentioned in the papers of Arpetti and colleagues (2013, 2014a). From the set of interviews they collected, Laurillard and colleagues (2013) conclude that, for HE teachers, building on the work of peers is accepted practice, therefore a valid learning design environment must support the retrieval of existing designs and mediate their adaptation; Bennett and colleagues (2011) reached similar conclusions. The same position can be found in papers where the focus is the evaluation of a tool (e.g. Conole, 2014; Masterman \& Manton, 2011) and results indicate that this feature is positively evaluated when available; according to Hernández-Leo et al. (2013), the possibility to (co-)create designs by reusing existing ones is judged of interest, and this practice seems to be preferred to the creation of new designs from scratch.

Support for co-operation among teachers: According to Papanikolaou and colleagues (2016), the opportunity to obtain a peer evaluation of a developed design was positively considered by the teachers participating in the evaluation of the PeerLAND tool. Similarly, the opportunity provided by the LD platform adopted (ILDE ${ }^{3}$ ) to share one's own design (e.g., for comment or collaborative editing in small groups) was appreciated by participants in the METIS project workshops (Pozzi et al., 2015b). Sharing functionalities seem to be especially valued by those who work in institutions with a strong collaboration culture (Hernández-Leo et al., 2018).

Support for reflection: LD methods and tools provide the opportunity to carefully plan and structure learning activities and have the design available (in graphical or textual format) in every moment during and after the design phase. This is expected to help teachers in reflecting on the rationale behind the design of the activities, frame their work from a pedagogical view point, and come back after enactment to reflect on strengths and weaknesses of their design. According to Arpetti and colleagues (2014a), teachers consider support for reflection as an important feature of an LD tool. Support for reflection was also explored by Prieto and colleagues (2014), in contrast with support for practice (i.e., for putting ICT-enabled scenarios into practice); in this case, teachers expressed positive views regarding support both for pedagogical reflection and for concrete teaching practice.

Ease of use: The issue of usability is common to all ICT tools and is relevant for LD tools. The complexity of LD tools, in terms of usability, ranges from templates that can be easily filled by teachers without specific technical skills, to tools that require familiarity with ICTs and entail a certain learning curve. The importance of 'ease of use' was clearly expressed in the user requirements collected by Arpetti and colleagues (2014a) and is cited among the desirable features of a tool by Bennett and colleagues (2011). Usability is one of the most commonly valued parameters in the evaluation studies considered (e.g. Conole, 2014; Hernández-Leo et al., 2015; Katsamani \& Retalis, 2013; Mylonakis, Arapi, Moumoutzis, Christodoulakis, \& Ampartzaki, 2013) and is anyway cited as a paramount characteristic for LD tools (Levy, 2015).

Time saving: In the study by Arpetti and colleagues (2014a), economy in terms of time is cited among the requirements for use of an LD tool. The same is highlighted in two studies devoted to evaluation of one or more tools (Hernández-Leo et al., 2015; Prieto et al., 2014) even though, in the second case, only implicitly. Moreover, authoring systems integrating sequencing recommendation techniques were preferred to traditional authoring environments, since they allow teachers to save time during the authoring process (Verbert et al., 2012).

\footnotetext{
${ }^{3}$ https://ilde.upf.edu/
} 
Textual vs. graphical representation: Different LD tools allow representing designs using either graphical or textual representation. For example, in visualising the flow of activities, represented in the authoring phase, some tools make available a set of icons representing the different kinds of elements (e.g., tasks, resources) that can be combined for building a design (see, for example, CADMOS, Katsamani \& Retails, 2013), others are mainly based on textual representation, having the structure of a template to be filled in (see, for example, EDIT2, Sobreira \& Tchounikine, 2012). Teachers' seem to express divergent positions about the type of representation they prefer. . In several studies teachers seem to prefer a textual representation rather than a graphical one. This is reported by Arpetti et al., 2013, who found that the representation used to describe the learning design is basically textual. The same authors (Arpetti, Baranauskas, \& Leo, 2014b) found that the graphical representation of designs is not valued by teachers. Again, when this aspect is explored during the evaluation of a tool, findings are contrasting: in some cases, teachers seem not to appreciate it (Conole, 2014) while in others the visual metaphor proposed is positively valued (Katsamani \& Retails, 2013). According to Masterman \& Manton (2011) graphical representation seems to be preferred by teachers at the beginning of the design process.

Activate design thinking processes teachers are familiar with : According to Bennett and colleagues (2015), when designing, university teachers tend to accept support from colleagues of the same subject, especially within the same institution. Starting from Stark's findings (2000), the authors state that the strategy for improving teaching should build on beliefs of faculty groups and derive from the disciplines. In this sense, they state that design support tools should be based on the teachers' and institutional design culture. Similarly, Laurillard and colleagues (2013) highlight that design tools should support the way teachers approach their normal practice, even if the tool's ultimate aim is to enhance such practice.

\section{$R Q 2$. What are the main barriers to the adoption of $L D$ tools and the proposed design practices?}

Barriers to adoption are rarely openly explored in the analysed papers; instead, they were inferred from teachers' answers and comments. In the attempt to categorize barriers to provide a meaningful contribution, we have adopted the structure proposed by Ertmer (1999), who introduced two orders of barriers to technology integration: first order barriers are defined as extrinsic to teachers and are represented by the "types of resources (e.g., equipment, time, training, support) that are either missing or inadequately provided in teachers' implementation environments" (pag. 50); second order barriers, on the contrary, are intrinsic individual barriers, deeply ingrained and therefore not so easy to overcome. As we discuss in the following, first and second order barriers are sometimes intertwined.

\section{First order barriers}

Lack of institutional support: As Masterman \& Manton (2011) highlight, lack of support, hinders the adoption of all technology, and also represents an issue for LD tools. According to the authors, an important aspect is interoperability between the tool adopted and administrative and pedagogic systems, a factor which allows time and costs saving. Another aspect raised as influencing the uptake of a tool is the technological infrastructure made available by institutions (Pozzi et al., 2015a).

Lack of adequate teacher training: Integrating new learning design methods and tools entails a change in the current planning/design practice and in teaching itself; this change can hardly happen without specific training. Hernández-Leo and colleagues (2015) report that half of the teachers involved in their training asked for advanced follow-up training sessions to strengthen their 
confidence in the use of the tool. The need for ongoing support, especially from a technical viewpoint, was also expressed by participants in the METIS workshops (Pozzi, et al., 2015a).

Time/workload factors: These two aspects can evidently influence the use of a tool and the related design method and are linked to teachers' need to save time. Moreover, they can be seen as transversal to several barriers. Hernández-Leo and colleagues (2015) as well as Prieto and colleagues (2014) report that some teachers consider workload and time limits as an obstacle to tool adoption; time issues were cited by some of the participants in the METIS workshop who reported not having concluded the activities due to limited time (Pozzi et al., 2015a).

Conceptual complexity of method and tools: The issue of complexity remains controversial. Derntl and colleagues $(2010,2012)$ report that teachers with little or no previous IMS-LD specifications knowledge were able to solve a design task that required the use of all IMS-LD elements; therefore, the complexity of the specifications seems not to be an insurmountable barrier to its use for authoring, as is often surmised. The issue of complexity was also explored by Prieto and colleagues (2014), who compared tool perception and adoption intention of a group of teachers exposed to two tools with different levels of complexity. The order in which teachers were exposed to the tools seemed to affect tool appreciation and adoption intention. Specifically, the teachers who were exposed first to a tool with an easy interface tended to appreciate both the tools; on the contrary, the teachers exposed first to the more complex tool expressed less intention to adopt either of the tools after the workshop.

Adoption by peers: According to Masterman \& Manton (2011), communities of teachers have a pivotal role in supporting the diffusion of a tool. The same point is raised by Hernández-Leo and colleagues (2015), who found that the level of participation of colleagues in the community affects teachers' intention of use. Moreover, they identified the degree of adoption by peers as an open challenge.

\section{Second order barriers}

Use of ICTs in teaching practice: This factor is highlighted both by Arpetti and colleagues (2014a) and by Prieto and colleagues $(2013,2014)$. The issue seems to be significant for at least a couple of reasons: 1) It affects the perceived advantage of using the tool (advantages in terms of automatic implementation of the design in the Learning Management System, where available); and 2) It affects attitudes towards using the tool (participant teachers that did not normally use ICTs in teaching were less likely to adopt authoring tools and tended to appreciate tools with an easier interface).

Teachers' motivation: Intrinsic motivation is considered crucial for the uptake of a tool, which should show a clear benefit to the teacher. Institutional imposition,that makes teachers feel their autonomy is limited, can demotivate them (Masterman \& Manton 2011). Without speaking explicitly about motivation, Prieto and colleagues (2014) highlighted that teachers make a costbenefit analysis when considering usage and adoption of design tools.

\section{Discussion}

As already mentioned, both needs and barriers have been mainly indirectly explored in the literature, therefore the studies considered in this review frequently had different aims from the investigation of these two aspects. Moreover, the majority of the studies have been carried out in HE contexts, while a small number present mixed sample. The prevalence of studies in HE can be explained considering the growing pressures that teachers in that context are experiencing in terms 
of quality expectations and introduction of innovations (Goodyear, 2015). Nevertheless, even at other school levels, technology integration is becoming a major issue and teachers can clearly benefit from a focus on their design practice and needs.

As to the users' needs (RQ1), the results confirm that flexibility is a highly desirable quality for a tool. The term flexibility seems to be adopted in relation to multiple aspects (e.g. flexible in relation to the context or pedagogical model, flexible in runtime changes, etc.). Teachers appear to be warry of constraints that tools may impose on the creative process of design, but, in the end, a tool should also scaffold teachers in the design process. This aspect is intertwined with how the tool aligns with teachers' design thinking. Ease of use and a concrete help in saving time (qualities that can be considered an expression of usefulness or collateral to it) were cited among needs and are, certainly, important qualities for a tool. This opens a due reflection about (a) the weight that perceived usefulness can have in the decision to adopt a tool and (b) the need to provide teachers with the opportunity to familiarize with LD tools (through training or long-term support) in order to appreciate their usefulness. As to features supporting collaboration (sharing, reusing and cocreating), it is worth noting that the possibility to share and reuse one's own designs or designs created by others is cited among needs and inferred by analysis of actual design practices, while the possibility to co-create is positively valued when available. The issue of representation (graphical or textual) is widely debated but remains controversial. The preference for textual representation might derive from the teachers' established tendency to draft their designs in text format on paper, a process that can be easily reproduced in tools based on templates to be filled in. Moreover, tools proposing graphical representations might present some complexity: the proposed representations may not be intuitive for teachers and require a non-negligible effort to learn.

Regarding the barriers to adoption (RQ2), papers were analysed in the light of Ertmer's(1999) organization in first and second order barriers. Among the first order barriers, context (whether institutional or the professional community) plays a role in adoption and is an aspect to be considered: top-down institutional imposition can be ineffective (Masterman \& Manton, 2011), but at the same time the lack of support from the institution can be considered a barrier to adoption (Pozzi, 2015a). The presence of an active community of peers seems to positively affect adoption intentions. Adequate training seems to be another crucial aspect, which can also entail the creation of a community in which teachers share LD experiences and designs, as proposed by Asensio-Pérez and colleagues (2014). While the conceptual complexity of methods and tools has been considered a barrier for some time, the results reported here seem not to confirm this assumption. However, it is worth noting that two of the studies (Derntl et al., 2010; Derntl et al., 2012) are focused on the IMS-LD specification, which represents a specific case that can't be generalized. Moreover, the studies refer to the learnability of the IMS-LD specifications and not to the teachers'/practitioners' intention to adopt them. Time and workload can be considered transversal factors and are specular to the need to save time. As second order barriers, we identified two main issues in the analysed papers: the use of ICTs in teaching practice and, last but not least, motivation. Motivation is scarcely explored in the analysed literature, suggesting that it might deserve more attention and more thorough analysis. The panorama of needs and barriers outlined in this review reflects a complexity of partially interrelated factors. Some barriers can be seen as specular to needs, for example the issue of tool complexity represents a barrier and, at the same time, teachers consider a tool ease of use as very important. Similarly, the social/commuity aspect is expressed both as a need and a barrier: teachers call for tools supporting collaboration with others and the lack of support of the community is seen as an obstacle. If we revisit the categorization presented in the introduction, some of the elements listed in this review can be included in the three main categories proposed 
(LD tools features, teachers' mindset and training). However, according to our analysis, other elements such as contextual and individual factors, were not included or at least remain overshadowed in that categorization. To conclude, the findings from this literature review may not appear to break new ground per se since most of the issues presented are well known in the research field. The contribution given here lies in the systematization of these findings, the identification of possible gaps to be covered and the formulation of recommendations to cover these gaps.

Firstly, despite the fact that teachers are the final users of the proposed methods and tools, few of the studies selected for this survey directly explore teachers' actual design practices and needs. Two reasons may provide an explanation for this. On the one hand, LD researchers with a technological background tend to focus more on technical aspects of the tools (mainly usability issues) while leaving educational aspects in the background. On the other, researchers with an educational background dedicate more attention to teachers' needs and actual practices but they are more interested in exploring the effectiveness of their proposal, since they propose new methods for supporting the integration of the innovation. Therefore, in both cases, studies remain focused on specific tools and methods and rarely investigate the theme per se.

The lack of studies specifically dedicated to barrier analysis can be considered a gap in the field. In spite of the attention devoted to the issue of tool adoption, just one paper (Prieto et al., 2014) explored perceived barriers to adoption directly with teachers/practitioners themselves, while the others mainly focus on the evaluation of specific tools. This often led to considerations and actions oriented to the specific cases with a narrow impact. Moreover, almost none of the studies adopts a comparative approach, which in fact could be productive for identifying the perceived strengths and weaknesses of different tools and methods in the eyes of teachers/practitioners. Here again, the reason may be the primary need to evaluate the effectiveness of the proposed methods and tools, overshadowing the general issue of adoption. Secondly, adoption is a complex process that needs be monitored in the long term but, probably due to several constraints on time, costs, teachers' availability, etc. almost no studies envisage a follow-up: while teachers are asked about their experience with a tool or a method immediately after a course or a practical experience, this is not repeated after a period in order to understand if the experience has had an impact and led to concrete adoption. A final reason could be a generally pessimistic view regarding the capacity of teachers to work as fully-fledged designers, or even the disenchantment of researchers after initial enthusiasm generated by the introduction of the IMS-LD technical specification.

Moreover, a few of the surveyed studies explored barriers at individual level and, in particular, the aspect of motivation which could be relevant for designing and implementing actions to foster tools and methods adoption.

Some recommendations directed to the research community can be derived from this analysis of the literature. First of all, the current research focus on LD for introducing a more design-based approach to teaching practices should be balanced with complementary studies aimed at gaining better understanding of current teaching practices and beliefs (see, for example, Bennett and colleagues, 2015 and 2017). This could help in the development of artefacts that can guide the process of design and, at the same time, improve it, finding a balance between actual and optimal practices (Laurillard et al., 2013). This could also be explored in relation to teachers' motivation to adopt LD.

Research effort should be dedicated to exploring barriers to reach transversal conclusions and address them effectively. The focus on usability of specific tools may distract the attention away from factors that are tool-independent (e.g. institutional support or personal factors).Broadening of 
focus, especially in the direction of individual/personal factors would follow the path indicated by Straub (2009). Summarizing the main theories in the field of technology adoption and diffusion, the author concludes that technology adoption is a complex, inherently social and developmental process, where the characteristics of the specific innovation is just one of the factors affecting the decision to adopt: individual and contextual factors also play an important role. Along this line, addressing cognitive, affective and contextual concerns becomes fundamental for supporting adoption, and these should be the object of study.

The methodological issue of empirical data collection is challenging. To address both the needs and barriers, studies comparing different methods and tools, like the one proposed by Prieto and colleagues (2014), can support reflection on desirable features of tools and possible solutions to foster teachers' adoption of LD tools and methods. If possible, these comparative studies should not be limited to an experimentally designed phase (within a controlled context such as a workshop or seminar) but should also include a follow-up phase in which teachers can use the tools in their own teaching contexts, in authentic conditions. Such studies could represent a valid source of data, because only by testing and comparing different solutions can teachers express their preferences and really become aware of their needs in terms of features offered. Finally, in general, more follow-up or long-term studies, involving teachers who have experienced or have been trained with one or more LD tools could shed light on the factors or tool features affecting the decision to adopt a design method and/or tool. Indeed, these teachers could be considered informants and provide valuable contributions to research in the field.

Clearly, considerable efforts would be required to conduct these kinds of studies and this should not be underestimated. Follow-up studies, in particular, require considerable investments and suffer from the drop out of participants in the long term, but despite this, they seem to us the way to go so as to collect meaningful information.

Indeed, comparative studies could benefit from collaboration between institutions that have developed LD methods and tools and that are currently carrying out training initiatives with teachers. For follow-up studies, the creation of online communities and the provision of long term support by trainers can increase the opportunities for data collection.

However systematic, this literature review does not presume to be exhaustive. It presents some limitations, since it represents an initial effort in defining a research thread, which could be further explored in the future.

The decision to search the extant literature indexed on databases was guided by the intent to collect only reliable, quality, peer-reviewed contributions. However, project reports were also searched on Google to include "grey literature" that could complement the coverage of research work provided by bibliographic databases. Other types of documents, such as presentations, white papers or dissertations were not taken into account. Future analyses may include more thorough coverage of the grey literature. Secondly, the idea was to explore the most up to date research by considering the 2010-17 time frame; as a result, some important contributions can have been excluded because published previously. This gap could also be covered in future studies.

\section{Acknowledgments}

This research has been partially funded by the Spanish State Research Agency (AEI) and the European Regional Development Fund, under project grants TIN2014-53199-C3-2-R and TIN201785179-C3-2-R, the Regional Government of Castilla y León and the European Regional 
Development Fund, under project grant VA082U16, the European Commission, under project grant 588438-EPP-1-2017-1-EL-EPPKA2-KA and the University of Valladolid (UVa).

There is no conflict of interest

\section{References}

Arpetti, A., Baranauskas, M. C. C., \& Leo, T. (2013). Learning design and teaching practice: Outlining an iterative cycle for professional teachers. Proceedings of the IEEE 13th International Conference on Advanced Learning Technologies, ICALT 2013, 280-284.

http://doi.org/10.1109/ICALT.2013.87

Arpetti A., Baranauskas M.C.C., \& Leo T. (2014a). Eliciting requirements for Learning Design tools. In: Rensing C., de Freitas S., Ley T., Muñoz-Merino P.J. (eds) Open Learning and Teaching in Educational Communities. EC-TEL 2014. Lecture Notes in Computer Science, vol 8719. Springer, Cham http://doi.org/10.1007/978-3-319-11200-8_1

Arpetti, A., Baranauskas, M. C. C., \& Leo, T. (2014b). Grounding Learning Design on teaching practice: The LEDITA Learning Design Tool for Italian Language teachers. Proceedings of the 14th IEEE International Conference on Advanced Learning Technologies, 706-710.

http://doi.org/10.1109/ICALT.2014.205

Asensio-Pérez, J. I., Dimitriadis, Y., Prieto, L. P., Hernández-Leo, D., \& Mor, Y. (2014). From idea to VLE in half a day: METIS approach and tools for learning co-design. Proceedings of the Second International Conference on Technological Ecosystems for Enhancing Multiculturality, 741-745. http://doi.org/10.1145/2669711.2669983

Asensio-Pérez, J.I., Dimitriadis, Y., Pozzi, F., Hernández-Leo, D., Prieto, L.P., Persico, D., Villagrá-Sobrino, S.L. (2017). Towards teaching as design: exploring the interplay between fulllifecycle learning design tooling and teacher professional development. Computers \& Education, $114,92-116$

Bennett, S., Agostinho, S., \& Lockyer, L. (2015). Technology tools to support learning design: Implications derived from an investigation of university teachers' design practices. Computers \& Education, 81, 211-220. http://doi.org/10.1016/j.compedu.2014.10.016

Bennett, S., Agostinho, S. \& Lockyer, L. (2017). The process of designing for learning: understanding university teachers' design work. Educational Technology Research and Development, 65(1), 125-145. https://doi.org/10.1007/s11423-016-9469-y

Bennett, S., Thomas, L., Agostinho, S., Lockyer, L., Jones, J., Susan Bennett, A., \& Harper, B. (2011). Understanding the design context for Australian university teachers: implications for the future of learning design. Learning Media and Technology, 36(2), 151-167. Retrieved from http://ro.uow.edu.au/edupapers/180

Celik, D., \& Magoulas, G. D. (2016). Teachers' perspectives on design for learning using computer based information systems: A systematic Literature Review. Paper presented at the UK Academy for Information Systems 21st Annual Conference (UKAIS, 2016).

Conole, G. (2013). Designing for Learning in an Open World. New York: Springer Verlag. http://doi.org/10.4324/9780203127568

Conole, G. (2014). Using Compendium as a tool to support the design of learning activities. In A. Okada, S. S. Buchingam, \& T. Sherborne (Eds.), Knowledge Cartography. Advanced Information 
and Knowledge Processing (pp. 23-45). Springer London. http://doi.org/10.1007/978-1-4471-64708

Conole, G. (2015). Theoretical underpinnings of learning design. In Dalziel, J, (ed.) Learning design: conceptualizing a framework for teaching and learning online. Routledge, Abingdon, pp. 42-62

Derntl M., Neumann S., Griffiths D., Oberhuemer P. (2010). Investigating teachers' understanding of IMS Learning Design: Yes they can!. In: Wolpers M., Kirschner P.A., Scheffel M., Lindstaedt S., Dimitrova V. (eds) Sustaining TEL: From Innovation to Learning and Practice. EC-TEL 2010. Lecture Notes in Computer Science, vol 6383. Springer, Berlin, Heidelberg

Derntl, M., Neumann, S., Griffiths, D. \& P. Oberhuemer (2012). The conceptual structure of IMS Learning Design does not impede its use for authoring. IEEE Transactions on Learning Technologies, 5(1), 74-86.

Dimitriadis, Y., \& Goodyear, P. (2013). Forward-oriented design for learning: illustrating the approach. Research in Learning Technology Supplement, 21, 1-13.

Ertmer, P. A. (1999). Addressing first- and second-order barriers to change: Strategies for technology integration. Educational Technology, Research and Development, 47(4), 47-61.

Goodyear, P. (2015). Teaching as design. HERDSA Review of Higher Education, 2, 27-50.

Hermans, H., Janssen, J., \& Koper, R. (2016). Flexible authoring and delivery of online courses using IMS Learning Design. Interactive Learning Environments, 24(6), 1265-1279.

Hernández-Leo, D., Asensio-Pérez, J. I., Derntl, M., Pozzi, F., Chacón-Pérez, J., Prieto, L. P., \& Persico, D. (2018). An Integrated Environment for Learning Design. Frontiers in ICT, 5, 9. doi: 10.3389/fict.2018.00009

Hernández-Leo D., Chacón J., Prieto L.P., Asensio-Pérez J.I., \& Derntl M. (2013) Towards an Integrated Learning Design Environment. In: Hernández-Leo D., Ley T., Klamma R., Harrer A. (eds) Scaling up Learning for Sustained Impact. EC-TEL 2013. Lecture Notes in Computer Science, vol 8095.pp. 448-453, Springer, Berlin, Heidelberg. http://doi.org/10.1007/978-3-642-40814-4_37

Hernández-Leo D., Moreno P., Carrió M., Chacón J., \& Blat J. (2015) Ldshake and the "Biologia en context" teacher community across high schools. In: Maina M., Craft B., Mor Y. (eds) The Art \& Science of Learning Design. Technology Enhanced Learning. SensePublishers, Rotterdam

Kalantzis, M., \& Cope, B. (2010). The Teacher as Designer : pedagogy in the new media age. ELearning and digital media, 7(3), 200-222. https://doi.org/10.2304/elea.2010.7.3.200

Katsamani, M., \& Retalis, S. (2013). Orchestrating learning activities using the CADMOS learning design tool. Research in Learning Technology, [S.1.], v. 21,1-12. Retrieved from http://www.researchinlearningtechnology.net/index.php/rlt/article/view/18051

Kitchenham, B., \& Charters, S. (2007). Guidelines for performing Systematic Literature reviews in Software Engineering Version 2.3. EBSE Technical Report

Laurillard, D. (2012). Teaching as a design science. Building pedagogical patterns for learning and technology. Routledge. 
Laurillard, D., Charlton, P., Craft, B., Dimakopoulos, D., Ljubojevic, D., Magoulas, G., ... Whittlestone, K. (2013). A constructionist learning environment for teachers to model learning designs. Journal of Computer Assisted Learning, 29(1), 15-30. http://doi.org/10.1111/j.13652729.2011.00458.x

Levy P. (2015) Technology-Supported Design for Inquiry-Based Learning. In: Li M., Zhao Y. (eds) Exploring Learning \& Teaching in Higher Education. New Frontiers of Educational Research (289-304). Springer, Berlin, Heidelberg http://doi.org/10.1007/978-3-642-55352-3

Masterman, E., \& Manton, M. (2011). Teachers' perspectives on digital tools for pedagogic planning and design. Technology, Pedagogy and Education, 20(2), 227-246.

http://doi.org/10.1080/1475939X.2011.588414

Mor, Y., \& Craft, B. (2012). Learning design: Reflections upon the current landscape. Research in Learning Technology, 20, 85-94. http://doi.org/10.3402/rlt.v20i0.19196

Mor, Y., Craft, B., \& Maina, M. (2015). Learning Design: Definitions, Current Issues and Grand Challenges. In: Maina M., Craft B., Mor Y. (eds) The Art \& Science of Learning Design.

Technology Enhanced Learning (pp. 9-26). SensePublishers, Rotterdam. http://doi.org/10.1007/978-94-6300-103-8

Mylonakis, M., Arapi, P., Moumoutzis, N., Christodoulakis, S., \& Ampartzaki, M. (2013). Octopus: A collaborative environment supporting the development of effective instructional design.

Proceedings of the Second International Conference on E-Learning and E-Technologies in Education (ICEEE), 260-265. http://doi.org/10.1109/ICeLeTE.2013.6644385

Neumann, S., Klebl, M., Hernández-Leo, D., de la Fuente Valentín, L., Hummel, H...Oberhuemer, P. (2010). Report of the Results of an IMS Learning Design Expert Workshop. International Journal Of Emerging Technologies in Learning, 5(1), 58-72.

Papanikolaou K.A., Gouli E., Makrh K., Sofos I., \& Tzelepi M. (2016). A peer evaluation tool of Learning Designs. In: Verbert K., Sharples M., Klobučar T. (eds) Adaptive and Adaptable Learning. EC-TEL 2016. Lecture Notes in Computer Science, vol 9891. 193-206. Springer, Cham http://doi.org/10.1007/978-3-319-45153-4

Pozzi, F., Ceregini, A., Persico, D., Sarti, L., Brasher, A., Chacón-Pérez, J.,...Serrano M.A. (2015a). D5.3: Report on second formative evaluation round. METIS Project Deliverable. Retrieved from http://websites.cardet.org/metis/resources/deliverables/D5_3.pdf

Pozzi, F., Ceregini, A., Persico, D., Sarti, L., Brasher, A., Hernández-Leo D., \& Asensio-Pérez, J.I. (2015b). D5.4: final evaluation report. METIS Project Deliverable. Retrieved from http://websites.cardet.org/metis/resources/deliverables/D5_4.pdf

Prieto, L. P., Asensio-Perez, J. I., Munoz-Cristobal, J. A., Dimitriadis, Y. A., Jorrin-Abellan, I. M., \& Gomez-Sanchez, E. (2013). Enabling teachers to deploy CSCL designs across distributed learning environments. IEEE Transactions on Learning Technologies, 6(4), 324-336.

http://doi.org/10.1109/TLT.2013.22

Prieto, L. P., Tchounikine, P., Asensio-Pérez, J. I., Sobreira, P., \& Dimitriadis, Y. (2014). Exploring teachers' perceptions on different CSCL script editing tools. Computers \& Education, 78, 383-396. http://doi.org/10.1016/j.compedu.2014.07.002 
Rodriguez-Triana, M. J., Prieto, L. P., Vozniuk, A., Shirvani Boroujeni, M., Schwendimann, B. A., Holzer, A. C., \& Gillet, D. (2017). Monitoring, awareness and reflection in blended technology enhanced learning: a systematic review. International Journal of Technology Enhanced Learning, 9 (2-3), 126-150.

Sobreira, P., \& Tchounikine, P. (2012). A model for flexibly editing CSCL scripts. International Journal of Computer-Supported Collaborative Learning, 7, 1-26.

Stark, J. (2000). Planning introductory college courses: Content, Context and form. Instructional Science, 28, 413-438.Straub, E. (2009). Understanding technology adoption: Theory and future directions for informal learning. Review of Educational Research, 79,625-649

Verbert, K., Ochoa, X., Derntl, M., Wolpers, M., Pardo, A., \& Duval, E. (2012). Semi-automatic assembly of learning resources. Computers \& Education, 59(4), 1257-1272.

http://doi.org/10.1016/j.compedu.2012.06.005

Vygotsky, L.S. (1962). Thought and Language. Cambridge, MA: MIT Press.

Vygotsky, L.S. (1978). Mind in Society. Cambridge, MA: Harvard University Press.

Voogt, J., Westbroek, H., Handelzalts, A., Walraven, A., McKenney, S., Pieters, J., \& de Vries, B. (2011). Teacher learning in collaborative curriculum design. Teaching and Teacher Education, 27(8), 1235-1244. http://doi.org/10.1016/j.tate.2011.07.003 